\title{
A criminalização da homofobia
}

\section{Sandra de Mello Carneiro Miranda}

Mestre em ciências jurídicas e sociais pela Universidade Federal Fluminense UFF. Docente do Curso de Graduação em Direito do Centro Universitário de Barra Mansa - UBM.

\section{Gabriel de Oliveira Severino}

Discente do Curso de Graduação em Direito do Centro Universitário de Barra Mansa - UBM.

E-mail: gabriel_violino@hotmail.com 


\section{Resumo}

O presente trabalho tem como objetivos estudar e esclarecer mais detalhes sobre a Homofobia no Brasil e suas peculiaridades, indagando-se ser necessário ou não a criminalização da homofobia a partir de demonstração de estatísticas de casos , posicionamento do Código Penal, reflexões sobre a importância do papel da educação em nossas escolas e ainda o conceito do termo homofobia. A finalidade deste estudo é analisar o posicionamento do Estado diante a diversidade encontrada nos dias de hoje, preservando sempre a dignidade da pessoa humana.

Palavras Chave: Dignidade. Homofobia. Criminalização.

\section{Abstract}

The present work has as objective to do some studies and seek to clarify details about the homophobia in Brazil and its peculiarities, bringing the research that is necessary or not the Criminalization of homophobia, bringing statistics on the case, the positioning of the Penal Code, reflections of the importance of the role of education in our schools and the concept of the word homophobia.

Keywords: Dignity. Homophobia. Criminalization. 


\section{Introdução}

Este trabalho trata da criminalização da homofobia. Visa responder à questão se é necessário ou não criminalizar a homofobia para se dar uma proteção adequada aos homossexuais.

Discute-se se a criminalização da homofobia seria necessária para o reconhecimento das variadas condições sexuais do ser humano, visando à liberdade de escolha de orientação sexual e identidade de gênero, tendo em vista que integram a personalidade do indivíduo. No ordenamento jurídico brasileiro, já existem sanções penais previstas em lei, protegendo os direitos fundamentais, em que se encaixam a dignidade de pessoa humana, entre outros. Posto isso, qualquer crime cometido, receberá uma sanção, incluindo aqueles crimes cuja motivação é homofóbica, mas que não possuem uma proteção legal específica ficando à mercê da lei geral, não havendo uma proteção direcionada do Estado à comunidade LGBT.

O trabalho se justifica em razão do grande número de atos de violência praticados contra homossexuais, que são divulgados constantemente na mídia.

Percebe-se que não há uma segurança voltada para eles, pois muitos enxergam a homossexualidade como patologia, desde a época do Brasil colônia. Por isso, é importante a discussão de meios capazes de promover direitos e estabelecer deveres contra a discriminação, cuja motivação é preconceituosa, sendo que o grupo LGBT está aumentando de acordo com as estatísticas, deixando de ser um grupo pequeno e se tornando um grupo com maior abrangência.

Os objetivos são conceituar homossexualidade e homofobia, expor os números sobre a prática de condutas homofóbicas, analisar o princípio da dignidade da pessoa humana como fundamento para proteção aos homossexuais, estudar o papel da educação no combate à discriminação e verificar as propostas para a criminalização da homofobia. A metodologia usada será a teórica, com análise de dados sobre a violência mencionada, e cada seção abordará um dos objetivos traçados. 


\section{Homossexualidade}

A homossexualidade é uma característica de quem sente atração física, emocional e espiritual por outras pessoas do mesmo sexo. O termo homossexual foi criado por um jornalista austro-húngaro chamado Karl-Maria Kertbeny em 1868, acredita-se que desde a antiguidade já existiam pessoas com tal característica (CABRAL, 2003).

Em 1970, os psiquiatras afirmavam que a homossexualismo era uma doença mental causada por processos fisiológicos, por desvios da orientação sexual e ainda por má formação e identificação sexual. Em 1993, o termo foi mundialmente retirado da lista de doenças mentais, já que não havia provas que confirmassem a veracidade do pronunciamento, e foi declarado que a homossexualidade era uma forma natural de desenvolvimento sexual (CABRAL, 2003).

$\mathrm{Na}$ atualidade existem vários estudos biológicos e psicológicos que buscam respostas acerca da origem da homossexualidade. Ainda não há respostas definitivas para tais, mas o doutor Dean Hamer, geneticista e diretor de uma unidade de estrutura e regulação genética situada nos Estados Unidos, defende a existência de um gene responsável pela característica homossexual, para esse gene deu o nome de Gay1. Foi bem recebido e celebrado por alguns cientistas e criticado por outros. (CABRAL, 2003)

Se nos pautarmos pela explicação da homossexualidade ligada à hereditariedade, ou seja, em decorrência de fatores genéticos, poderíamos dizer que ela nasce junto com a humanidade. (CAPPELLANO, 2009)

\section{ORIENTAÇÃO SEXUAL E IDENTIDADE DE GENERO}

Orientação sexual diz respeito à atração que se sente por outros indivíduos. Ela geralmente também envolve questões sentimentais, e não somente sexuais. Assim, se a pessoa gosta de indivíduos do sexo oposto, fala-se que ela é heterossexual. Se a atração é por aqueles do mesmo sexo, sua orientação é homossexual. Há também aqueles que se interessam por ambos: os bissexuais. Pessoas do gênero masculino com orientação homossexual geralmente são chamadas de gays; e as do gênero feminino, lésbicas (SUPLICY, 1999). 
O termo orientação sexual é considerado mais apropriado do que opção sexual ou preferência sexual porque o termo "opção" indica que uma pessoa teria escolhido a sua forma de desejo. A psicologia moderna, embora não tenha consenso a respeito do que exatamente explica a sexualidade de um indivíduo, determina que a orientação sexual não possa ser mudada com terapias e não é uma escolha. A orientação sexual pode ser determinada por fatores biogenéticos, sejam questões hormonais ou genes que possam determinar essa predisposição. A visão prevalente é a de que a orientação sexual é biológica por natureza, determinada por um complexo jogo de fatores genéticos e desenvolvimento intrauterino. Alguns acreditam que a orientação sexual é estabelecida na concepção, portanto não uma escolha. Isto é, indivíduos não optam por serem heterossexuais, homossexuais ou bissexuais. Não há evidência suficiente para suportar a visão de que experiências na infância, criação, abuso sexual ou outros efeitos adversos em vida influenciem a orientação sexual (LEAL, 1997).

Já a identidade de gênero é a maneira como alguém se sente e se apresenta para si e para as demais pessoas como masculino ou feminino, ou ainda pode ser uma mescla, uma mistura de ambos, independentemente do sexo biológico (fêmea ou macho) ou da orientação sexual (orientação do desejo: homossexual, heterossexual ou bissexual). É a forma como nós reconhecemos a nós mesmo e desejamos que os outros nos reconheçam. Isso inclui a maneira de agir (jeito de ser), a maneira de se vestir, andar, falar (o linguajar utilizado) e também, de se vestir. A identidade de gênero é normalmente confundida com a orientação sexual. Por exemplo, é muito comum as pessoas travestis serem consideradas como homossexuais, pois, o fato dessas pessoas portarem, em seus corpos, elementos mais femininos, leva a grande maioria das outras pessoas a afirmarem que a travesti se sente, necessariamente, atraída por homens. Na realidade, a travesti pode se sentir atraída (orientação do desejo) tanto por homens, quanto por mulheres e por outras travestis. Ser travesti não determina a orientação do desejo da pessoa (PINHEIRO, 2015).

A identidade de gênero, por sua vez, costuma ser menos compreendida, ao passo que a orientação sexual se refere a outros, a quem nos relacionamos; a identidade de gênero faz referência a como nos reconhecemos dentro dos padrões de gênero estabelecidos socialmente. Existem dois sexos, mulher e homem, e dois gêneros, feminino e masculino. Embora a maioria das mulheres se reconheça no gênero feminino e a maioria dos homens no masculino, isso nem sempre acontece. Indaga-se, então, de 
pessoas cujo sexo biológico discorda do gênero psíquico: são os travestis e os transexuais. Existe muita confusão a respeito das relações entre orientação sexual e identidade de gênero, e a verdade é que não existe relação - são coisas completamente independentes. Uma pessoa de sexo biológico feminino pode se enquadrar no gênero masculino e se sentir atraído exclusivamente por homens. Ele seria, então, um homem transexual gay. Enfim, a confusão a respeito de orientação sexual e identidade de gênero se devem ao padrão que a sociedade impôs que temos a mania de querer aplicar a tudo (PINHEIRO, 2015).

\section{HOMOFOBIA}

O termo homofobia tem sido amplamente utilizado para a conceitualização do preconceito e discriminação contra indivíduos que apresentem orientação sexual diferente da heterossexual. Apesar do seu uso corrente no Brasil, são quase ignoradas a extensa discussão e as controvérsias teóricas em torno do termo desde que foi cunhado na década de 1970 nos Estados Unidos (COSTA, 2015).

As questões de identidade e orientação sexual são ligadas à própria humanidade, inerentes ao ser humano. Seja decorrente de fatores biológicos, genéticos, psicológicos, ou da própria liberdade individual de escolha, a identidade e orientação sexual são características do ser humano que podem variar em cada indivíduo, da mesma forma que a cor da pele, o gênero, a origem étnica e a opção religiosa. Não se pode aceitar discriminação fundamentada em característica intrínseca aos seres humanos, como o pluralismo sexual (RAMOS, 2015).

Ainda que determinada característica se observe em uma minoria da população, não pode ser-lhe negada a dignidade da pessoa humana, direito elevado ao status de fundamento do nosso Estado Democrático de Direito. A homofobia é caracterizada pelo sentimento de medo, aversão e repulsa contra as pessoas LGBT (Lésbicas, Gays, Bissexuais, Travestis, Transexuais e Transgêneros). Nesse sentido, a homofobia pode ser comparada a outras fobias como a claustrofobia, acrofobia e hidrofobia, que são medos de lugares fechados, altura e água, respectivamente (RAMOS, 2015).

Entretanto, a expressão do sentimento homofóbico é extremamente reprovável, assim como o racismo e a xenofobia. Mas a homofobia possui outra face cognitiva ou social, em que não há rejeição à população LGBT, mas uma indiferença em relação às 
diferenças de direitos entre heterossexuais e LGBT, isto é, não há intolerância aos LGBT, mas uma tolerância às hostilidades por eles sofridas (RAMOS, 2015).

\section{Condutas Homofóbicas}

Segundo o último relatório divulgado pela ONG (Organização NãoGovernamental) baiana, que são organizações, criada por pessoas que trabalham voluntariamente em defesa de uma causa, o Grupo Gay da Bahia, em 2010, foi documentado 260 assassinatos de gays, travestis e lésbicas no Brasil; 62 a mais que em 2009 (198 mortes), um aumento 113\% nos últimos cinco anos (122 em 2007). Dentre os mortos, 140 gays (54\%), 110 travestis (42\%) e 10 lésbicas (4\%). O Brasil confirma sua posição de campeão mundial de assassinatos de homossexuais: nos Estados Unidos, com 100 milhões a mais de habitantes que nosso país, foi registrado 14 assassinatos de travestis em 2010, enquanto no Brasil, foram 110 homicídios. Anota ainda o supracitado relatório que nos três primeiros meses de 2011 já foram documentados 65 homicídios contra homossexuais (CERQUEIRA, 2014).

Ainda conforme os dados apurados pelo Grupo Gay da Bahia, o Estado baiano, pelo segundo ano consecutivo, lidera a lista com 29 homicídios; seguida de Alagoas, com 24 mortes; Rio de Janeiro e São Paulo com 23 cada. Rio Grande do Norte e Roraima registraram apenas um assassinato cada. Se relacionarmos a população total dos Estados com o número de LGBT assassinados, aponta o relatório, Alagoas repete a mesma tendência dos últimos anos: é o Estado que oferece maior risco de morte para os homossexuais, cujo número de vítimas ultrapassa o total de todos os estados juntos da região Norte do país. Maceió, igualmente, é a capital onde mais gays são assassinados: com menos de um milhão de habitantes, registrou 9 homicídios, contra 8 em Salvador (população de 3 milhões de habitantes), 7 no Rio de Janeiro (população de 6 milhões de habitantes) e surpreendentemente, 3 mortes na cidade de São Paulo, com 10 milhões de habitantes (CERQUEIRA, 2014).

Destaque para a região Nordeste como sendo a mais homofóbica: abriga 30\% da população brasileira e registrou 43\% dos LGBT assassinados. 27\% desses crimes letais ocorreram no Sudeste, $9 \%$ no Sul, 10\% no Centro-Oeste, 10\% no Norte. Por conseguinte, conclui o relatório que o risco de um homossexual do Nordeste ser assassinado é aproximadamente 80\% mais elevado do que no Sul/sudeste, 36\% desses 
homicídios foram cometidos nas capitais, 64\% nas cidades do interior. Já quanto à idade, $7 \%$ das vítimas eram "menores de idade" ao serem assassinados, 14\% com menos de 20 anos; $46 \%$ menos de 30 anos, $6 \%$ na terceira idade. A faixa etária que apresenta maior risco de assassinato situa-se entre 20-29 anos: 28\%. A vítima mais nova tinha 14 anos: a travesti Érica, morta com 14 tiros no Centro de Maceió e o mais velho, Josué Amorim, 78 anos, aposentado, assassinado por três rapazes a golpes de facão em sua residência em União dos Palmares (AL). Por fim, tem-se que 43\% dos homossexuais foram mortos a tiros, $27 \%$ com facas, $18 \%$ vítimas de espancamento ou pedradas e $17 \%$, sufocados ou enforcados. Vários desses crimes revelam o ódio da homofobia, sendo praticados com requintes de crueldade, tortura, empalamento ou castração (CERQUEIRA, 2014).

Nesta pesquisa, foi verificada que, para $70 \%$ da população em geral, a discriminação contra LGBT é ou seria um problema das pessoas, não exigindo nenhuma ação do governo para combater essa situação. $54 \%$ da população em geral não sabem da existência de lei no Brasil que considere crimes atos de discriminação contra LGBT e 83\% não conhece ou nunca ouviu falar do Programa do Governo Federal "Brasil sem Homofobia". Ademais, destaque-se que somente 5\% dos entrevistados da população geral acredita que os direitos de LGBT's são totalmente respeitados no Brasil, o que denota uma crença social de que a criação ou a efetividade dos direitos das minorias sexuais não seriam problemas do Estado, legitimando um discurso discriminatório socialmente aceito pela maioria (CERQUEIRA, 2014).

Segundo pesquisas realizadas no Rio de Janeiro, foram mortas, em 2016, 343 pessoas lésbicas, gays, bissexuais, travestis e transexuais (LGBT) no Brasil, um recorde levantado pelo Grupo Gay da Bahia (GGB) nos 37 anos em que compila anualmente o número de vítimas fatais da homofobia. Isso significa que, aproximadamente a cada 25 horas, pelo menos uma pessoa com estas orientações sexuais é assassinada no país, conforme adiantou a coluna de Ancelmo Gois. O GGB alerta: a falta de registros ainda é um grave problema no Brasil, que ainda carece de registros centralizados e oficiais do tipo, portanto a realidade possivelmente é muito mais dramática (ALVIM, 2017).

Em 2000, foram registrados 130 homicídios; e em 2010, 260. Outra virada na tendência nos últimos anos ocorre a nível regional: o Norte vem liderando o número de assassinatos por habitantes, tirando a triste liderança de décadas da região Nordeste. Em 2016, foram computados 3,02 homicídios a cada um milhão de habitantes no Norte, seguido pelo Centro-Oeste $(2,56)$, Nordeste $(1,94)$, Sul $(1,24)$ e Sudeste $(1,19)$. Em 
números absolutos a nível estadual, estão na frente São Paulo (49 assassinatos), Bahia (32), Rio de Janeiro (30) e Amazonas (28) (ALVIM, 2017).

\section{Direitos Humanos e Diversidade Sexual}

Para que se entenda qualquer discussão sobre Direitos Humanos, é necessária a compreensão de que a base de qualquer direito está ancorada à Constituição Federal, a norma maior do Estado Brasileiro. Principalmente porque é de lá que se depreende que todos os seres humanos nascem livres e iguais em dignidade e direitos, e que os direitos humanos são universais, indivisíveis e inter-relacionados. A livre orientação sexual e identidade de gênero são essenciais para a dignidade de cada pessoa e não devem ser motivo de discriminação ou abuso (RAMOS, 2015).

A violação de direitos humanos que atinge pessoas por causa de sua orientação sexual ou identidade de gênero, real ou percebida, constituem um padrão global e consolidado, que causa sérias preocupações. Podemos destacar como exemplo destas violações, tortura, maus tratos, agressões sexuais, estupros, invasão de privacidade, detenção arbitrária, negação de oportunidade de emprego, educação e sérias discriminações em relação ao acesso a outros direitos humanos e são, com frequência, agravadas por outras formas de violência, ódio, discriminação e exclusão, como aquelas baseadas na raça, idade, religião, deficiência ou sistema econômico, social ou de outro tipo (RAMOS, 2015).

\section{PRINCÍPIO DA DIGNIDADE DA PESSOA HUMANA}

O princípio da dignidade da pessoa humana estatui que a pessoa humana mereça tratamento digno pelo simples fato de ser humana. O homem deve ser um fim em si mesmo e não um meio para a consecução dos projetos alheios, uma vez que ele não tem um preço, mas é um ser dotado de dignidade. A dignidade é um valor espiritual e moral inerente à pessoa, que se manifesta singularmente na autodeterminação consciente e responsável da própria vida e que traz consigo a pretensão ao respeito por parte das demais pessoas, constituindo-se um mínimo invulnerável que todo estatuto jurídico deve assegurar, de modo que, somente excepcionalmente, possam ser feitas 
limitações ao exercício dos direitos fundamentais, mas sempre sem menosprezar a necessária estima que merecem todas as pessoas enquanto seres humanos (DIAS, 2000).

Não há como se considerar uma vida digna, quando o indivíduo é discriminado de maneira arbitrária e preconceituosa, por isso é que, intimamente ligado ao princípio da dignidade da pessoa humana, estão a garantia da isonomia, no sentido de que não é admissível qualquer forma de tratamento discriminatório, e a garantia da identidade pessoal de cada pessoa, que se materializa na sua liberdade de crença, de consciência, de proteção à sua intimidade e honra, na sua vida privada, bem como o direito de auto determinação sobre assuntos que dizem respeito a sua esfera particular (COMPARATO, 2008).

Do princípio da dignidade da pessoa humana também deriva o princípio fundamental ao respeito, que consiste na liberdade da autonomia individual, para que a pessoa viva sua vida como bem entender, inclusive, colocando o seu afeto onde achar que deve, ou seja, incumbe a cada indivíduo formular as escolhas de vida que levarão ao desenvolvimento de sua personalidade. Este respeito deve ser assegurado pelo Estado e pela sociedade como um todo. Qualquer discriminação baseada na orientação sexual configura claro desrespeito à dignidade da pessoa humana, o que infringe o princípio maior da Constituição Federal. Infundados preconceitos não podem legitimar restrições a direitos, o que acaba por referendar estigmas sociais e fortalecer sentimento de rejeição, além de ser fonte de sofrimento a quem não teve a liberdade de escolher nem mesmo o destino de sua vida, pois a orientação sexual independe de opção e não altera por ato de vontade (RODRIGUES, 2016).

\section{- papel da educação em direitos humanos no respeito à diversidade}

A educação em direitos humanos é um processo sistemático e de variadas dimensões que visa formar uma cultura de direitos humanos que priorize a igualdade entre todas as pessoas, e ao mesmo tempo, o respeito à diferença. Tal processo cria condições para o exercício de uma prática cidadã, que no cotidiano, se revela com a formação de sujeitos conscientes de seu papel na sociedade e aptos a reivindicar a igualdade de acesso aos direitos humanos fundamentais. Não podemos esquecer que educação em direitos humanos é, sobretudo, educar-se. (LOURO, 1997) É 
conscientizar-se dos valores que são necessários à construção de uma cultura de respeito ao ser humano e à sua dignidade, valores estes que estão tão "fora de moda" numa sociedade que cada vez mais parece estar governada pela violência e opressão. Mas só a consciência não basta. É necessário também aplicar este conhecimento no mundo exterior. Ou seja, é necessário tomar este saber comprometido com a promoção de um mundo mais justo e solidário, e pautá-lo como base para uma ação de transformação da realidade. Em outras palavras, é necessário aliar conteúdo e prática, e não há nada melhor para fortalecer esta conexão do que educar com o exemplo. (RIBEIRO, 2012)

Educar para a diversidade, é educar, portanto, para o respeito às diferenças entre toda e qualquer pessoa. A escola, seja ela pública ou privada, se mantém fechada, a respeito da homossexualidade em suas dependências, buscando repelir, excluir o diferente, bem como tratar a homossexualidade como aberração ou doença (NASCIMENTO, 2015).

\section{COMBATE À DISCRIMINAÇÃO}

Desde 1997, o Brasil recebeu o registro como um dos países que mais comete violência contra homossexuais. Uma sociedade que não garante os Direitos Fundamentais de todas as pessoas não é uma sociedade igualitária, livre, democrática e justa. Grandes passos estão sendo dados quanto à legislação brasileira e a garantia dos direitos da população de LGBT, porém, é preciso mais. E é por isso, que a Secretaria de Estado dos Direitos Humanos e Cidadania do Maranhão em parceria com a Secretaria de Direitos Humanos da Presidência da República lançou uma cartilha, como produto do Projeto Centro de Referência em Direitos Humanos, desenvolvido pela SEDIHCMA (Secretaria de Estado de Direitos Humanos e Cidadania do Maranhão) que garante a criação e a manutenção de um espaço de atendimento, orientação e acompanhamento das vítimas de violação dos Direitos Humanos fundamentais contra as populações caracterizadas pela diversidade sexual, étnica, racial, cultural, de gênero e religiosa, com ênfase para atendimento aos casos de homofobia do Estado do Maranhão. (CUNHA, 2016)

Outra característica importante sobre a criação da cartilha criada pelo Grupo Gay da Bahia é de, defender os interesses da comunidade homossexual da Bahia e do Brasil, denunciando todas as expressões de homofobia (ódio aos homossexuais), lutando 
contra qualquer forma de preconceito e discriminação contra gays, lésbicas, travestis e transexuais, trabalhando assim na prevenção do HIV e AIDS junto à nossa comunidade e outros grupos vulneráveis à epidemia, conscientizando o maior número de homossexuais da necessidade urgente de lutar por seus plenos direitos de cidadania, fazendo cumprir a Constituição Federal que garante tratamento igualitário a todos os brasileiros (FRANCO, 2008).

Atenta à gravidade das manifestações de caráter homofóbico, a Secretaria de Direitos Humanos da Presidência da República (SDH) reforçou o atendimento pelo Disque 100 - Disque Direitos Humanos. Segundo o último balanço da secretaria, entre janeiro e abril de 2015, foram registradas 356 denúncias de violações de direitos humanos entre a população LGBT no País. Em 2014, foram registradas 1.013 denúncias (CUNHA, 2016).

\section{Criminalizar a homofobia}

\section{PROJETO DE LEI DA CÂMARA 122/2006}

Depois de oito anos, o debate sobre a criação de uma lei de criminalização da homofobia avança com dificuldade no Congresso. Em janeiro deste ano, o Projeto de Lei 122, chamado PL da Homofobia, acabou arquivado no Senado. Para os defensores da criação da lei, a esperança reside no novo projeto de autoria da deputada Maria do Rosário (PT-RS). O projeto 7582/2014 está em tramitação na Comissão de Constituição e Justiça (CCJ) da Câmara e tipifica crimes de ódio, preconceito e intolerância contra diferentes grupos (PINTO, 2011).

Os números da violência contra a população LGBT apontam, de fato, para a urgência de uma ampla discussão sobre o assunto pela sociedade civil. De acordo com o Relatório Anual de Assassinatos de Homossexuais no Brasil, elaborado pela organização Grupo Gay Bahia (GGB), em 2014, foram registradas 326 mortes de gays, travestis e lésbicas, incluindo nove suicídios. O número é 4,1\% maior do que o registrado no ano anterior, quando foram contabilizadas 313 mortes. Uma média de um assassinato a cada 27 horas (COUTINHO, 2015).

Projeto de lei da Câmara 122 de 2006, (PLC 122/2006) ou PL 122, também conhecida como lei anti-homofobia, foi um polêmico projeto de lei brasileiro 
apresentado pela então deputada Iara Bernardi (PT - SP). O projeto de lei tinha por objetivo criminalizar a homofobia no país e foi arquivado após passar oito anos no Senado sem obter aprovação. Era considerado- por importantes juristas, entre eles dois ministros do Supremo Tribunal Federal (STF)- como constitucional. A aprovação imediata de alguma legislação específica para a criminalização da homofobia é apontada como "urgentemente" necessária no país por alguns especialistas. Para algumas entidades cristãs (católicas e protestantes), o projeto fere a liberdade religiosa e de expressão, por prever cadeia (até 5 anos) para quem criticar publicamente a homossexualidade, seja qual for a razão. No entanto, isso não constava no texto da lei (PINTO, 2011).

Tal projeto teve início da Câmara dos Deputados, sendo proposto no dia 7 de agosto de 2001 sob denominação de Projeto de Lei (PL) 5003/2001, em que propunha sanções às práticas discriminatórias em virtude de orientação sexual. Após tramitação na Comissão de Constituição e Justiça (CCJ) da Câmara onde foram condensados a este outro projeto com teor semelhante, o PL 5003/2001 sofreu alterações propostas pelo então Deputado Luciano Zica relator do projeto na comissão (PINTO, 2011).

A nova versão apresentada, saiu do CCJ e foi aprovada em Plenário 34 Após aprovação na Câmara já em 2006 o projeto foi encaminhado ao Senado Federal onde recebeu nova numeração, passando a tramitar como PLC 122/2006, antes de ir à votação no Plenário a Mesa Diretora determinou que o projeto vinculasse por duas comissões, na Comissão de Direitos Humanos e na Comissão de Constituição, Justiça e Cidadania (PINTO, 2011).

\section{ALTERAÇÃO NO CÓDIGO PENAL (CP)}

$\mathrm{Na}$ esfera penal, a proposta é modificar o $\S 3^{\circ}$ do artigo 140 , acrescentando punição à injúria cometida em virtude de gênero, sexo, orientação sexual ou identidade de gênero (PINTO, 2011).

O Projeto de Lei da Câmara n. ${ }^{0}$ 122/06 visa criminalizar a discriminação motivada unicamente na orientação sexual ou na identidade de gênero da pessoa discriminada. Se aprovado, irá alterar a Lei de Racismo para incluir tais discriminações no conceito legal de racismo - que abrange, atualmente, a discriminação por cor de pele, etnia, origem nacional ou religião (PINTO, 2011). 
A discriminação por orientação sexual é aquela cometida contra homossexuais, bissexuais ou heterossexuais unicamente por conta de sua homossexualidade, bissexualidade ou heterossexualidade, respectivamente. A discriminação por identidade de gênero é aquela cometida contra transexuais e não transexuais unicamente por conta de serem ou não transexuais (respectivamente) (PINTO, 2011).

Discriminação e preconceito não se confundem. Enquanto o preconceito é um arbitrário juízo mental negativo, a discriminação o efetivo tratamento diferenciado de determinada pessoa por razões preconceituosas (arbitrárias). Assim, o PLC 122/06 punirá a discriminação, não o preconceito - lembrando, todavia, que ofender alguém por motivos preconceituosos implica discriminação contra a pessoa ofendida (VECCHIATTI, 2013).

\section{CRÍTICAS À CRIMINALIZAÇÃO DA HOMOFOBIA}

Embora haja uma crítica comum ao PLC n. ${ }^{\circ}$ 122/06 de que assassinar, agredir e ofender alguém já se configura em crime, não há criminalização específica da discriminação não violenta por orientação sexual ou por identidade de gênero (VECCHIATTI, 2016).

O crime de "constrangimento ilegal", que, em tese, pode ser usado para coibir a discriminação por orientação sexual ou por identidade de gênero, tem uma pena ínfima que não intimida as pessoas homofóbicas a não discriminar LGBTs. Pode-se fazer uma comparação com a Lei Maria da Penha: como bem diz Maria Berenice Dias, antes desta lei "era barato bater na mulher", pois a pena era inferior a dois anos e, portanto, bastava ao agressor pagar uma cesta básica para se livrar da pena privativa de liberdade (prisão). Pois bem, o mesmo pode ser dito quanto ao crime de constrangimento ilegal homofóbico: atualmente é barato discriminar LGBTs, pois as pessoas não são presas por tal conduta, limitando-se a ter que prestar algum serviço à comunidade ou pagar uma cesta básica, algo que historicamente tem se mostrado incapaz de intimidar as pessoas a não cometerem determinada prática delituosa (VECCHIATTI, 2016).

Muitos criminalistas criticam legislações penais "simbólicas", mas não é disso que aqui se trata, pois o PLC n. ${ }^{\circ}$ 122/06 respeita inclusive os ditames da ideologia do “Direito Penal Mínimo", defendida por tais criminalistas, na medida em que ele trata de um tema fundamental à vida em sociedade (o dever de tolerância ao próximo, que não 
pode ser discriminado pelo simples fato de ser diferente) e que não tem sido resolvido pelos demais ramos do Direito (São Paulo possui a Lei Estadual n.o 12.948/2001, que estabelece punições administrativas à discriminação homofóbica, como advertências e multas a pessoas físicas, aliadas a suspensões/cassações de licenças para estabelecimentos comerciais), razão pela qual não será ele uma legislação puramente simbólica. Toda lei tem um efeito simbólico - o de promover um valor e/ou reprimir a conduta contrária a tal valor - razão pela qual não se pode condenar o PLC n. ${ }^{\circ}$ 122/06 pela sua simbologia de combate às discriminações por ele condenadas (VECCHIATTI, 2016).

Assim sendo, a atividade sexual entre pessoas de sexos diferentes acaba por receber um tratamento preferencial: interpretada como referência e padrão em acordo com a lei natural, a hierarquia social é definida tendo a heterossexualidade como sexualidade normal, um modelo ser perseguido, elogiado e reproduzido. Para tal, a supervalorização de certos sujeitos em detrimento a outros é a responsável por uma violência simbólica, psicológica e/ou física resultado da construção de uma identidade estigmatizada e marginalizada dos indivíduos homossexuais que justificaria e legitimaria a sua desigualdade e, por consequência, as inúmeras violências protagonizadas por estes.

\section{Conclusão}

Com o término do trabalho, conclui-se que, é necessário sim criminalizar a homofobia. Pelo simples fato de que, o ódio contra pessoas homossexuais precisa ser erradicado, ou ao menos, diminuído, para que o homossexual possa sair livremente na rua, sem aquela preocupação de ser morto. Hoje em dia, muitas pessoas relevam esse problema e permitem que passe "despercebido"; porém, sabe-se que a homofobia existe, e as pesquisas que apontam isso diretamente, como por exemplo, o levantamento que um Grupo Gay da Bahia (GGB), que é o grupo mais antigo que luta pela defesa dos direitos humanos dos homossexuais no Brasil, constatou que a cada 27 horas um brasileiro LGBT morre vítima desse ódio e repulsa contra a orientação sexual do indivíduo.

Claro que, ainda existem pessoas que defendem a opinião de que não é necessária a criminalização da homofobia, pois as mesmas acham que já existam as leis que penalizam homicídio e lesão corporal, tendo em vista que, assim como a sociedade, os homossexuais também estão expostos à falta de segurança no Brasil. 
Mas, se formos analisar o caso, não é bem assim, pois o que o movimento LGBT está lutando é para que, além da criação de penas mais severas, tenha também outro papel importante para a sociedade, que é o de coibir declarações com teor ofensivo, e, nesse aspecto, nota-se que o Direito Penal, tem um efeito inibitório. Nada mais justo que aplicar uma pena com maior severidade a quem agride e mata LGBTs por ódio pelo simples fato de existirem e serem quem são.

Hoje é muito comum encontrarmos discursos de ódio serem tratados com muita simplicidade, e quando ocorrem esses ataques, não há leis para desnaturalizar esse tipo de violência. É nítido que, essas ofensas, agressões e discriminações não deixarão de existir do dia para a noite, mas, pelo menos, existirá uma lei contra a LGBTfobia, um jeito de mostrar a sociedade que o ódio e a repulsa não serão mais tolerados.

\section{Referências}

ALVIM, Mariana. Homofobia mata uma pessoa a cada 25 horas; Norte tem maior índice 2017 Disponível em https://oglobo.globo.com/sociedade/homofobia-mata-uma-pessoacada-25-horas-norte-tem-maior-indice-20819002 Acesso em maio/2017.

CABRAL, Gabriela. Homossexualidade. 2003 Disponível em http://mundoeducacao.bol.uol.com.br/psicologia/homossexualidade.htm Acesso em maio/2017.

CAPPELLANO, Luiz Carlos A História da Homossexualidade Breve Histórico da Homossexualidade 2009 Disponível em https://homofobiabasta.wordpress.com/ahistoria-da-homossexualidade/ Acesso em maio/2017.

CERQUEIRA, Marcelo. Grupo Gay da Babia: A cada 25 horas, 1 homossexual é assassinado no Brasil, diz pesquisa do GGB. 2014 . Disponível em: https://grupogaydabahia.com.br/.

RAMOS, Miguel Os direitos humanos, a Declaração Universal dos Direitos Humanos de 1948 e o pensamento filosófico de Norberto Bobbio sobre os direitos do homem. 2015 Disponível em http://www.ambito-juridico.com.br/site/?n_link=revista_artigos_ leitura\&artigo_id=5147\&revista_caderno=15. 
COSTA, Ângelo Brandelli; Nardi, Henrique Caetano Homofobia e preconceito contra diversidade sexual: debate conceitual 2015 Disponível em

http://pepsic.bvsalud.org/scielo.php?script=sci_arttext\&pid=S1413-

389X2015000300015 Acesso em maio/2017.

COMPARATO, Fábio Konder. A afirmação histórica dos direitos humanos. 6 ed. São Paulo: Saraiva, 2008.

COUTINHO, Genilson GGB registra 326 assassinatos de gays em 2014 Disponível http://www.doistercos.com.br/ggb-registra-326-assassinatos-de-gays-em-2014/ Acesso em Maio/2017.

CUNHA, Carolina Homofobia: preconceito, violência e crimes de ódio. 2016 Disponível em https://vestibular.uol.com.br/resumo-das-disciplinas/atualidades/homofobiapreconceito-violencia-e-crimes-de-odio.htm. Acesso em maio/2017.

DIAS, Maria Berenice. Liberdade sexual e os Direitos Humanos. Revista Jurídica da Universidade de Franca, n. 05, ano 03, novembro, 2000.

FRANCO, Deputado Alberto - GLBT MA, Movimento - Cartilha de esclarecimento de Leis - Assuma seus Direitos. 2008.

LEAL, Isabel Pereira (1997). Sexualidade e parentalidade (pensar hoje o que se vem pensando) - Actas do 1o Colóquio de Psicologia Social Clínica. Lisboa: Instituto Superior de Psicologia Aplicada.

LOURO, Guacira Lopes. Gênero, sexualidade e educação: uma perspectiva pós estruturalista. 2. ed. Rio de Janeiro: Vozes, 1997.

NASCIMENTO, Anderson Kleber Ensaio Sobre O Preconceito. 2015 Disponível em https://books.google.com.br/books?id=Qh5OCgAAQBAJ\&dq=\%C3\%89+conscientizar se + dos+valores+que + s $\% \mathrm{C} 3 \% \mathrm{~A} 3 \mathrm{o}+$ necess $\% \mathrm{C} 3 \% \mathrm{~A} 1$ rios $+\% \mathrm{C} 3 \% \mathrm{~A} 0+$ constru $\% \mathrm{C} 3 \% \mathrm{~A} 7 \% \mathrm{C} 3$ $\% \mathrm{~A} 3 \mathrm{o}+\mathrm{de}+$ uma+cultura+de+respeito+ao+ser+humano+e+\% $\mathrm{C} 3 \% \mathrm{~A}+$ sua+dignidade, \&sourc e=gbs_navlinks_s Acesso em Maio/2017.

PINHEIRO, Lívia. Movimento pela Equiparação da LGBTfobia ao Racismo. Entenda Identidade de Gênero e Orientação Sexual, PLC 122, 2015. Disponível em 
http://www.plc122.com.br/orientacao-e-identidade-de-genero/entenda-diferencaentre-identidade-orientacao/\#axzz4m1ebOYC0 Acesso em Julho/2017.

PINTO, Ana Carla Costa. A Criminalização Da Homofobia À Luz Do Principio Da Dignidade Da Pessoa Humana. Monografia apresentada ao curso de Graduação em Direito da Universidade Presidente Antônio Carlos - UNIPAC, como requisito parcial obtenção do título de Bacharel em Direito. 2011 Disponível em http://www.unipac.br/site/bb/tcc/dir15.pdf Acesso em maio/2017.

RAMOS, Leandro Ferreira A Criminalização da Homofobia: uma pauta atual 2015 Disponível em https://conteudojuridico.com.br/print.php?content=2.53486 Acesso em maio/2017.

RIBEIRO, Mara Rejane; RIBEIRO, Getulio. Educação em Direitos Humanos e Diversidade Diálogos Interdisciplinares Maceió : EDUFAL, 2012 Disponível em http://www.ufal.edu.br/aedhesp/bibliteca-virtual/downloads/livro-educacao-humanose-diversidade-dialogos-interdisciplinares Acesso em maio/2017.

RODRIGUES, Marielle. Criminalização da homofobia e o conflito entre os principios constitucionais da igualdade e não discriminação e da liberdade de expressão. 2016

Disponível em https://juridicocerto.com/p/mariellerodrigues/artigos/criminalizacao-dahomofobia-e-o-conflito-entre-os-principios-constitucionais-da-igualdade-e-naodiscriminacao-e-da-liberdade-de-expressao-2122 Acesso em maio/2017.

SUPLICY, Marta (1999). Conversando sobre sexo. Petrópolis : Edição da autora, 1999.

VECCHIATTI, Paulo Roberto Iotti. Preconceito e Dano Moral. Ser chamado de homossexual não configura injúria, difamação e/ou dano moral. In: GUILHERME, Luiz Fernando do Vale de Almeida (org.). Responsabilidade Civil II, 2a Edição, São Paulo: Editora Fiuza, 2013, pp. 257-287.

VECCHIATTI, Paulo Roberto Iotti. Entenda o PLC. 2016 Disponível em 122/06http:/www.plc122.com.br/entenda-plc122/\#axzz4jUkUS6vD Acesso em Maio/2017. 